\title{
Mixed Method Research on Effective Psychological Counselor Characteristics and Empowerment Needs of Turkish School Counselors
}

\author{
Şule Baştemur* \\ Educational Science Department, Psychological Counseling and Guidance, Ordu \\ University, Turkey \\ ORCID: 0000-0003-3940-0565
}

\author{
Semra Uçar \\ Educational Science Department, Psychological Counseling and Guidance, Erciyes \\ University, Turkey \\ ORCID: 0000-0002-4395-9081
}

Article history

Received:

05.01.2021

Received in revised form: 07.05.2021

Accepted:

22.05.2021

Key words:

Effective school counselor characteristics;

Empowerment; supervision training
The study aims to examine the characteristics and empowerment needs of effective psychological counselors with the opinions of school counselors. Explanatory sequential design which is one of the mixed methods was used in the study. In the quantitative part of the study, the data was collected from 194 females, 100 males, in total 294 school counselors with simple random sampling method; in the qualitative part from 9 school counselors through criterion sampling. As the quantitative data collection tools, Effective Counselor Characteristics Assessment Scale and Empowerment Scale; as qualitative data collection tool, semi-structured interview form were used. For data analysis, multiple regression analysis and content analysis were used. According to the results, self-awareness, good intentions, flexibility sub-scales of effective psychological counseling characteristics and therapy training variable from demographic form were determined as significant predictors $(58.7 \%)$. In the qualitative part of the study, two main themes (Empowerment Needs and Psychological Counselor Characteristics) and four sub-categories for each theme (Non progressive to Develop, Differences in Job Description and Perception, Negative Personality Traits, Lack of Knowledge and Skill, Illusions in Psychological Counselor Perception, Non-professional Good Intentions, Low Self-awareness, Lack of Skill and Specialization) were determined. The obtained findings were discussed in the context of empowerment needs and supervision training of psychological counselors in Turkey, and suggestions were offered accordingly.

\footnotetext{
*Correspondency: sulebastemur@odu.edu.tr
} 


\section{Introduction}

Empowerment is a key concept used by different disciplines and has many definitions. According to McWhirter (1991; 1998) empowerment is about increased assertiveness or other self-management skills, positive human growth and change processes which simultaneously affect the individual and the community. Empowerment is especially related to people or groups who are powerless and focuses on some main processes. These are, to be aware of the power dynamics at work in their life context, develop the skills and capacity for gaining some reasonable control over their lives which they exercise without infringing upon the rights of others, and which coincides with supporting the empowerment of others in their community (McWhirter, 1994).

When empowerment is defined from the psychological counseling perspective, itfocuses on different points in various areas of psychological counseling. Some theorists emphasize it more in terms of power (Perkins and Zimmerman, 1998), while others pinpoint the personal growth aspect, (McWhirter, 1991), justice (Lyddon, 1995), oppression on women (Marecek, 2001) and advocacy for color clients (Lee, 1991). In a broadest sense, psychological empowerment is considered as one of the general goals of the counseling process (McWhirter, 1991) which focuses on clients' growth and healing (McWhirter, 1998). Thus, strengthening in the counseling process involves gaining control over the life of the client and making changes that support psychological wellbeing (Gammel and Stoppard, 1999).

Definition of empowerment highlights that psychological counselors need empowerment in the counseling process. This happens in two stages for school counselors. First one is the process which emphasizes the need for school counselors' personal empowerment and the second is the need for a comprehensive school counseling program (HipolitoDelgado and Lee, 2007). For the first stage, personal empowerment includes many important concepts such as critical consciousness, positive identity, and taking social action (Carr, 2003). The second stage of empowerment in counseling is about the need for a comprehensive school counseling program because counselor educators have a critical position for empowerment (McWhirter, 1998). First of all, psychological counselor educators are responsible to introduce the concept of empowerment to their students. Thus, psychological counselors should gain personal empowerment first. Then, they help their clients to empower themselves. This situation can increase the empowerment of the society in the long term which is one of the purposes of the counseling.

When talking about empowerment in psychological counselors, it is also necessary to consider their effective psychological counseling characteristics (EPCC). Because being a professional also requires having a certain level of professional competence. According to McWhirter (1998), comprehensive components are collaboration, competence, context, community and critical consciousness for psychological counselors. When these five components are evaluated, empowerment of counselors is directly connected to EPCC. The main reason for this is the relationship between empowerment, counseling skills, and counselor education (McWhirter, 1998). McWhirter (1991) indicates that empowerment is directly related to both developing psychological counselors' skills and having control over their personal life. An effective psychological counselor (EPC) is defined as someone who can create a balance between interpersonal and counseling skill 
competencies and successfully integrate their personal and scientific competences (Carkhuff, 2011; Cormier and Cormier, 1991; Ivey and Ivey, 2003). For this reason, it can be said that empowerment is affected by counseling qualities. Amongst the qualities required by an effective support giver, efficiency, energy, flexibility, support, good intentions and self-awareness become the prominent ones (Cornier and Cornier, 1991). In order to offer an effective service, a psychological counselor is expected to have cognitive competence, be open to learn, have the intellectual competence to satisfy the needs of the client, be able to adapt to new things, have the energy to be emotionally and physically self-sufficient in the process, be flexible for different methods, assure the client that they can help, be supportive, show good intentions by considering the benefit of the client and have high level of self-awareness to check on themselves while these occur (Cormier and Cormier, 1991; Cormier et al., 2009). This indicates the importance of the relationship between EPCC and empowerment, but EPCC are also related to other variables as a broad concept.

Another concept that affects psychological counselors' professionalism is supervision. Supervision training is one of the determining factors in providing with quality help in the context of individual, educational and group receiving services when psychological counseling qualifications are considered. Supervision which is an inseparable part of psychological counselor education is accepted as a significant process especially in terms of obtaining and improving professional skills (Borders and Brown, 2006). Improving psychological counselors both in their professions and in terms of personality which is in direct proportion to the concept of empowerment, giving them psychological counselor proficiency and maintaining the therapeutic relationship with the client are among the main aims of supervision (Bernard and Goodyear, 2004). Supervision which is not provided effectively adversely affects the psychological improvements of the counseling students (Worthington, 2006) since the candidates deeply comprehend psychological counseling skills through psychological counseling applications and reinforce them thanks to supervision (Hill et al., 2007). Therefore, empowerment, supervision and having EPCC can be directly related.

The program used in psychological counseling education in Turkey is based on the American system, and up-dates are partly applied in parallel with needs. All the psychological counselors graduate from a general program without having any field expertise. Along with preferably working in different institutions, almost all of them work as school counselors in the institutions that are under the Ministry of National Education. In Turkey, the syllabus for compulsory courses of Psychological Counseling and Guidance bachelor's degree program is generally the same for every program offered at universities and basic psychological counseling skills are taught in this process of education (Poyrazli et al., 2013). Although empowerment, supervision and having EPCC are related to each other, the counselor education program adopted in Turkey have some problems with these concepts. First, there is no course which only focuses on school counselor candidates' empowerment in the program. Second, even though all the counseling programs focus on the effective counseling skills such as efficiency, energy, flexibility, support, good intentions and self-awareness, there is no research about these qualities of Turkish school counselors. Last, in the bachelor's degree programs determined by the Higher Education Council in Turkey [YÖK] (2007), Psychological Counseling Practice with Individuals course is compulsory lesson in every university. 
Although this course is defined as compulsory in every university, the content of course does not own a standard in every higher education institution (Akkoyun, 1995; Yeşilyaprak, 2009), but the general application includes students' having supervision support in the lesson context and providing counseling services. However, how and in which quality the supervision training is given or whether it is given in every program are unknown and the academicians who give supervision training use their expertise that they gain in the context of their personal experiences, supervision training of their bachelor's or master's degree program or the therapy training that they pay (Siviş-Çetinkaya and Karairmak, 2012). In a study where supervision training levels in the psychological counseling education programs in Turkey was analyzed, it was determined that $45.6 \%$ of the participants reported that they received a supervision training, whereas $54.2 \%$ of the participants reported that they did not receive a supervision training (Anjel and Özkan, 2009). Even though the problems related to supervision practices are well known in Turkey, the studies on supervision in psychological counseling field are rather limited (Aladağ and Bektaş, 2009). Limited studies about the supervision of the psychological counselor focus on whether supervision in counselor education is given in general (Koçyiğit-Özyiğit and İşleyen, 2016; Sivis-Çetinkaya and Karaırmak, 2012; Y1lmaz and Voltan Acar, 2015) or through the assessment of supervision models (Erkan-Atik, Arıc1 and Ergene, 2014; Ery1lmaz and Mutlu, 2018; Meydan, 2015).

When all the problems are evaluated, it can be said that the counselors who are empowered at different areas (personal, educational, technical and so on) will also increase their psychological counseling skills. In order to develop EPCC in them, it is necessary to determine the existing power dynamics, develop their skills, ensure control over their own lives, and improve their own personal life skills. All these concepts are related to counselors' empowerment. Thus, the purpose of this study is to determine the professional, personal and academic characteristics of psychological counselors and to identify the points they need to empower. For this purpose, the research questions are as below:

(1) How do school counselors' EPCC, supervision and therapy training affect their empowerment needs?

(2) In what ways does this effect help school counselors to share their counseling qualifications and empowerment needs?

\section{Method}

\section{Research Model}

The study aims to examine the EPCC and empowerment needs of psychological counselors with the opinions of school counselors more deeply. Therefore, explanatory sequential design which is one of the mixed methods was used in the study. With this design, first of all, quantitative data are obtained and analyzed; afterwards, the qualitative process is conducted considering the results of quantitative analysis. Quantitative findings play a more determining role in approaching the findings related to the data obtained using sequential timing. In the evaluation of quantitative and qualitative data, what is learnt through combining the obtained data is revealed (Creswell and Plano-Clark, 2015). 


\section{Participants}

In the quantitative part, which is the first part of the study, simple random sampling method was used with the group consisting of school counselors who have equal possibility to be included in the sampling (Taherdoost, 2016). In the study, the data was collected from 194 females, 100 males, that is, in total 294 school counselors. In order to reach the sampling, half of the data was collected through online, through Google forms. Web based research studies provides researchers with the possibility to gather information directly, easily and more cheaply through social media, e-mail, texting and internet groups when compared to mailing or gathering information face-to-face (Andrews et al., 2003). The participant information related to the quantitative part of the study is presented in Table 1.The data were collected between the 2019-2020 academic years.

Table 1. Demographic Information of School Counselors

\begin{tabular}{llll}
\hline Variable & Level & N & \% \\
\hline Gender & Female & 194 & $\% 66$ \\
& Male & 100 & $\% 34$ \\
Educational & Bachelor's & 223 & 76 \\
Background & Master's & 64 & 22 \\
& PhD & 7 & 2 \\
Experiences as a & 0-5 Years & 113 & 38 \\
Psychological & 6-10 Years & 99 & 34 \\
Counselor & $11-15$ Years & 46 & 16 \\
& 16 Years and above & 36 & 12 \\
Supervision Training & Yes & 197 & 67 \\
& No & 97 & 33 \\
Therapy Training & Yes & 134 & 46 \\
& No & 160 & 54 \\
\hline
\end{tabular}

According to the data in Table 1, when the demographic features of the participants are examined, it can be observed that the number of female participants is twice more than the male participants', the majority of the participants are bachelor's degree graduates, and their experiences as a school counselor concentrates on the first five years and the second five years. The number of participants who received the supervision training during their bachelor's and master's degree is twice number of participants who did not receive the supervision training. The percentage of the participants who received therapy training independent from their university education and the percentage of the participants who did not receive therapy training independent from their university education are close to each other whereas the majority consists of the one who did not receive a therapy education.

On the other hand, in the qualitative part of the research, criterion sampling which is one 
of the purposeful sampling methods was deployed. Conscious choices are significant in order to reveal richer content in terms of knowledge in the qualitative research (Palinkas et.al., 2015). As for the participant criteria, the participants in the qualitative part consist of individuals who took part in the quantitative part of the study; these individuals who voluntarily participated should have professional experiences related to different institutions and masses. The participants consist of 4 females and 5 males; that is, in total 9 participants. Two of the participants received therapy training after graduation, one of the participants did not have supervision and therapy training, one of the participants has a $\mathrm{PhD}$ degree and two of the participants are master's students. During the interviews, four of the participants worked at a Counseling and Research Center, two of the participants worked at a primary school, one of the participants worked at a high school, and one worked at a secondary school. Their experience as a school counselor in the field ranges between 5 to 15 years.

\section{Data Collection Tools}

As quantitative data collection tools, "Effective Counselor Characteristics Assessment Scale" and "Empowerment Scale" were used along with "Demographic Information Form" prepared by the researcher. The qualitative data collection tools of the study consisted of semi-structured interview form developed by the researchers.

\section{Effective counselor characteristics assessment scale (ECCAS)}

The scale, which İkiz and Totan (2014) was developed by İkiz and Totan (2014) in order to determine self-awareness, intellectual efficiency, flexibility, energy, support and good intentions characteristics that a psychological counselor may need in terms of an effective service. There are 26 items and 6 sub-scales, and the scale also gives the total score. The lowest score to obtain from the scale is 26 , and the highest score is 130 . The internal consistency and test-retest coefficients of the scale are .80 for intellectual efficiency, .73 for energy, .70 for flexibility, .78 for support, .63 for good intentions, .79 for self-awareness, and .90 for overall scale. The Cronbach Alpha values in the current study were respectively found as $.90, .82, .92, .90, .87, .89$ and .97 .

\section{Empowerment scale}

The scale, which was developed by Rogers, Ralph and Salzer (2010) and adapted into Turkish language as a short form by Çakır and Bugay (2017), consists of 25 items. The scale is evaluated as total score and has four sub-scales. The reliability coefficients are .71 for self-worth and control over life, .54 for power-powerlessness, .69 for community activism and autonomy, .58 for righteous anger and .75 for overall scale. The Cronbach Alpha values in the current study were respectively found as $.91, .26, .93, .76$ and .85 .

\section{Demographic information form}

In the form, questions intending to obtain information regarding gender, age, education level, experience as a school counselor, psychological counseling practice with supervision conducted with an individual and/or group, being engaged in paid therapy 
training after bachelor's degree were included in order to gather information about the demographics of individuals.

\section{Semi-structured interview form}

The first half of the form consists of the questions prepared after literature reviews. The second half of the form was created according to quantitative data results. Expert opinion is given by 3 psychological counselors and 3 academicians at the psychological counseling department. The operability of the questions was also checked with the first two interviews, and it was seen that there was no need for a revision. Considering the quantitative findings, the researchers asked the participants to take into consideration both themselves and their colleagues that work in the same field and to answer questions related to their empowerment needs (What are the things that you and your colleagues that work in the field need for empowerment? What are the individual and professional effects of these needs? What can be done about this? and others), qualities of an EPC (What is your and your colleagues' positions in terms of EPC? How do you evaluate the situation that good intentions, self-awareness and flexibility which are among the EPCC are the factors that affect the empowerment needs? What do you think about the situation that pinpoints intellectual efficiency, energy and not being supportive do not affect the empowerment needs? and so on) and their education (How do you evaluate the situation that while the obtained therapy training affects the empowerment needs, supervision does not affect them?).

\section{Data Analysis}

For data analysis, multiple regression analysis was used in the quantitative part of the study whereas content analysis was used in the qualitative part of the study. In the determination of the demographic and continuous variables that will be included in the multiple regression analysis, the correlation analysis results were used as reference. Continuous and categorical variables related to the total score of empowerment needs were entered in the multiple regression analysis. In the estimation that is made by adding more than one variable, multiple regression analysis was employed. Before analyzing data, they were examined in line with regression analysis assumptions. It was observed that the skewness and kurtosis values of the variables were within the limits of \pm 1 . Since it is in this value range, it is accepted as meeting the normal distribution count (Tabachnick \& Fidell, 2013). Based on Menard's (2002) suggestion, the multicollinearity assumption was checked with tolerance values (should be more than .20), and variance influence factor (VIF; should be less than 4). The correlations (should be less than .90) between dimensions were also examined (Field, 2009). Multicollinearity assumption was met as correlations among all of the dimensions for independent variables except gender and dependent variable were not higher than .74 (between .12-.74), the highest VIF value was 6 and tolerance values were all higher than .98 (ranged from .17-.98).

The interview content that is obtained face-to-face and recorded were written down as a document and the content of the answers to the questions were scrutinized. Repeated words and sentences were excluded, and the data was cleaned. The definitions that are obtained this way is a process of subjective evaluation by classifying them systematically (Hsieh and Shannon, 2005). The analyses were carried out by researchers separately and 
compared; also, two different experts on the field expressed their opinions, and the common variables were determined as the theme categories in the qualitative part. The reliability for the qualitative findings were obtained with this process. Interview content analyses, which were converted into written texts to ensure the reliability of the findings obtained in the qualitative research, were carried out independently among the researchers. The internal consistency values in this research were found to be .90 . This value, which is calculated as the same number of decisions /total number of decisions, also gives an idea of how much the researchers adhere to the materials (Miles \& Huberman, 1994).

\section{Results}

\section{Quantitative Findings}

Descriptive statistics and bivariate correlations 
Table 2. Descriptives, Bivariate Correlations, and Reliabilities of the Study Variables (N=294)

\begin{tabular}{|c|c|c|c|c|c|c|c|c|c|c|}
\hline & $\begin{array}{l}1 . \\
\text { Self- } \\
\text { worth }\end{array}$ & $\begin{array}{l}2 . \\
\text { Power }\end{array}$ & $\begin{array}{l}3 . \\
\text { Activism, } \\
\text { Autonomy }\end{array}$ & $\begin{array}{l}4 . \\
\text { Righteous } \\
\text { Anger }\end{array}$ & $\begin{array}{l}5 . \\
\text { Self- } \\
\text { awareness }\end{array}$ & $\begin{array}{l}6 . \\
\text { Good } \\
\text { intention }\end{array}$ & $\begin{array}{l}7 . \\
\text { Supporting }\end{array}$ & $\begin{array}{l}8 . \\
\text { Flexibility }\end{array}$ & $\begin{array}{l}9 . \\
\text { Energy }\end{array}$ & $\begin{array}{l}10 . \\
\text { Intellectual } \\
\text { Efficiency }\end{array}$ \\
\hline 1. & - & .08 & $.87 * *$ & $.76 * *$ & $.61 * *$ & $.65 * *$ & $.65 * *$ & $.67 * *$ & $.61 * *$ & $.58 * *$ \\
\hline 2. & & - & $.13^{*}$ & .02 & $-.12^{*}$ & -.07 & -.03 & -.05 & -.09 & -.04 \\
\hline 3. & & & - & $-.79 * *$ & $.70 * *$ & $.69 * *$ & $.69 * *$ & $.65 * *$ & $.52 * *$ & $.58 * *$ \\
\hline 4. & & & & - & $-.57^{* * *}$ & $-.57 * *$ & $-.58 * *$ & $-.58 * *$ & $-.50 * *$ & $-.54 * *$ \\
\hline 5. & & & & & - & $.82 * *$ & $.78 * *$ & $.73 * *$ & $.62 * *$ & $.69 * *$ \\
\hline 6. & & & & & & - & $.83 * *$ & $.77 * *$ & $.66^{* * *}$ & $.71 * *$ \\
\hline 7. & & & & & & & - & $.87 * *$ & $.73 * *$ & $.79 * *$ \\
\hline 8. & & & & & & & & - & $.76 * *$ & $.80 * *$ \\
\hline 9. & & & & & & & & & - & $.73 * *$ \\
\hline 10. & & & & & & & & & & - \\
\hline M & 27.61 & 14.74 & 20.25 & 6.32 & 10.39 & 14.65 & 10.95 & 14.08 & 13.12 & 30.39 \\
\hline SD & 7.35 & 2.14 & 6.28 & 2.60 & 3.49 & 4.27 & 3.20 & 4.13 & 3.61 & 7.01 \\
\hline Range & $11-40$ & $7-20$ & $7-28$ & $3-12$ & $3-15$ & $4-20$ & 3.15 & $5-20$ & 4.20 & $10-40$ \\
\hline
\end{tabular}


The sample represented only higher level of self-worth $(\mathrm{M}=27.61, \mathrm{SD}=7.35)$, and righteous anger $(\mathrm{M}=6.32, \mathrm{SD}=2.60)$ of empowerment needs dimensions compared to possible range scores (Table 2). Any possible effect of participants' characteristics on empowerment needs was examined through an independent sample t-test and one wayANOVA. The results revealed that gender [ $\mathrm{t}(292)=-2.070, \mathrm{~ns}$.], having therapy training $[(\mathrm{t}(292)=-0.740, \mathrm{~ns}$.$] , having supervision training [(\mathrm{t}(291)=-0.767, \mathrm{~ns}$.$] , experience$ as a psychological counselor $[\mathrm{F}(3,290)=0.235$, ns.], were not significant variables for empowerment needs. The remarkable point was that power-powerlessness dimension had no significant relationship with most of the EPCC variables, though the rest of the associations were mainly significant (Table 2). The strongest (positive) correlation among empowerment needs and EPCC variables was between 'community, activism, autonomy' and 'self-awareness' $(\mathrm{r}=.70, \mathrm{p}<.01)$.

\section{Results of Multiple Regression}

The findings related to the sub-scales of psychological counselor qualities as the predictor of empowerment needs of school counselors and their therapy and supervision trainings with an individual and/or group which have an important place in the quality of the psychological counseling services reported by school counselors are presented in Table 3.

Table 3. Multiple Regression Analysis Results Related to the Estimation of Empowerment Needs of School Counselors

\begin{tabular}{llllllll}
\hline Variable & B & $\begin{array}{l}\text { Standard } \\
\text { Error B }\end{array}$ & $\beta$ & $\mathrm{t}$ & $\mathrm{p}$ & Binary r & Partial r \\
\hline Constant & 105.448 & 3.271 & & 32.236 & .000 & & \\
Self-awareness & -1.040 & 0.312 & -0.237 & -3.337 & $.001^{*}$ & -0.127 & -0.194 \\
Good Intentions & -0.735 & 0.283 & -0.205 & -2.597 & $.010^{*}$ & -0.099 & -0.152 \\
Supporting & -0.355 & 0.451 & -0.074 & -0.787 & .432 & -0.030 & -0.047 \\
Flexibility & -0.831 & 0.319 & -0.224 & -2.610 & $.010^{*}$ & -0.100 & -0.153 \\
Energy & -0.424 & 0.265 & -0.100 & -1.597 & .111 & -0.061 & -0.094 \\
Intellectual Efficiency & 0.029 & 0.154 & -0.013 & 0.191 & .849 & 0.007 & 0.011 \\
Therapy Training & -2.947 & 1.225 & -0.096 & -2.405 & $.017^{*}$ & -0.092 & -0.141 \\
Supervision Training & -0.635 & 1.273 & -0.020 & -0.499 & .618 & -0.019 & -0.030 \\
\hline
\end{tabular}

$\mathrm{R}=.766, \mathrm{R}^{2}=.587, \mathrm{~F}(8,292)=50.408, \mathrm{p}=.005$

As can be seen from Table 3, self-awareness, good intentions, flexibility sub-scales of EPCC and therapy training variable were determined as the significant predictors as a result of the multiple regression analysis related to the prediction of empowerment needs of school counselors. These variables indicate $58.7 \%$ of the total variance in empowerment needs variable. Also, there is a negative and significant correlation 
between empowerment need and therapy training and self-awareness, good intentions and flexibility subscales of EPCC $(\mathrm{R}=.766, \mathrm{R} 2 .=, 587 ; \mathrm{F}(8-292)=50.408, \mathrm{p}<.05)$.

\section{Qualitative Findings}

The qualitative findings in which the empowerment needs of school counselors and their perceptions about being an EPC are scrutinized are presented below.

\section{Theme 1. Empowerment needs}

In the psychological counseling services offered by school counselors for the population to which they serve, school counselors define their perceptions related to power dynamics. At the same time, this reveals the critical points of views in terms of the effects of empowerment needs on their daily life and professions. When the answers to the questions about empowerment needs are analyzed, four sub-categories emerge. These sub-categories forming empowerment needs are as follows: nonprogressive to develop, differences in job description and perception, negative personality traits and lack of knowledge and skill.

Nonprogressive to Develop: Although the school counselors evaluated the situation with a critical point of view in terms of their discontentment about insufficiency in the course of their work life events or transferring education to practice, they express their will to change this situation with their ventures and individual efforts. Three out of nine participants expressed their opinions about this.

“...young psychological counselors...they lose their excitement that they used to have when they first started. And they do not improve themselves or they are not open to developing themselves. If need be, this can be through trainings or being aware of new approaches. They are like 'ok we finished our bachelor's degree and let's close the doors (of the shop) '” $(P-1)$

Differences in job description and perception: It can be seen that school counselors do not take the institutions, populations and problematic issues that they will work with seriously enough. This situation means that they can define what their profession brings in parallel with their needs and perceptions without considering the limits of their competences adequately. Although everyone carries the same job title, each school counselor's way of applying this tittle show differences. Six out of nine participants expressed their opinions about this situation.

"Sometimes when people are insufficient in a field; for instance, if I am not good at psychological counseling, I can at least support the students as much as I can and protect them. If I can stand by them and tell them that they can come to see me whenever they want, and if can share some relaxing points from psychological counseling, so $I$ act according to my compass in doing the moral rather than the demands of the profession. " $(P-4)$

Negative personality traits: Although school counselors are in the role and identity of professionals, their services and their definition of themselves as professionals are not independent from the personality traits that they have. The negative personality traits sometimes may affect both the individual and the population that they give services. 
These negative traits are at times interwoven with the values of individuals. 4 out of 9 participants expressed their opinions about this situation.

"However, I think, they do not trust anyone since they do not behave
according to the work ethics of their job... since they are in the
business and they know that many people do not behave accordingly,
they say "there is nothing to be ashamed, you need to receive help"
to others but they are the ones who worry most about this because
unfortunately the majority do not obey the rules". (P-3)

Lack of knowledge and skill: Although the content of the bachelor's degree education of school counselors offer an extensive or needed professional practicum related to target population and their problems in terms of individual needs, the professionals in this very profession are responsible for acting in light of sufficient knowledge and skills in the field by seeking benefits of individual or individuals that they give their support services. However, in case there is the lack of training related to the need after the graduation, the psychological counselors may have problems primarily in their skills as well as their level of knowledge. This situation can harm the professional perception of the individuals towards themselves. In some situations, they can become a focus of solidarity or criticism among others that work in the field. Six out of 9 participants expressed their opinions about this situation.
"I feel weak in terms of practice. I mean in transferring what I learnt into practice. Being new in the profession might be affecting this. I don't know. Except for this, I think I am not good at reading something new or taking up new things; this can be a negligence." $(P-4)$.

\section{Theme 2. Psychological counselor characteristics}

This includes opinions towards how school counselors integrate academic, individual and professional factors, and what kind of a result this situation reveals in EPC services presented by school counselors to the population that they give services. When the answers to the questions related to the context of EPC were analyzed, four subcategories emerged. These sub-categories that form the psychological counselor qualities are as follows: illusions in psychological counselor perception, non-professional good intentions, low self-awareness and lack of skill and specialization.

Illusions in psychological counselor perception: Independent from the institutions and target population that school counselors work with, what kind of a service they give to the subject individual or individuals, the context of this, the responsibilities that form the job description and how they realize these partly indicate confusion. Sometimes with the effect of humanistic feelings and sometimes with the effect of service models (professional or unprofessional approach of another psychological counselor) that they encounter, they may define their professional identities. This tendency may come across in a unique style by being blended with trainings and competence in some cases. The school counselors also try to fill in the inadequacies in psychological counselor qualities with different competences or qualities. Five out of nine participants expressed their opinions about this situation.

"However, I think, it can be done by working right instead of working hard. Therefore, the theoretical or applied knowledge and 
skills required by the job fall behind... Rather than pointing to a welldefined job description, it is more like commitment/sentimentality which is very unprofessional." $(P-6)$

Non-professional good intentions: School counselors sometimes misinterpret positive and constructive professionalism which centers the welfare of the client while they exhibit EPCC. This can be seen as a psychological counselor characteristic style in which insufficient skills are replaced in situations where personal feelings (such as mercy and affection) are dominant. It is a fact that good intentions that is not in the professional line can become a part of situations in which individuals feel responsible for others; therefore, situations such as using this as a communication style or where dynamics are active with self are also possible. Six out of nine participants expressed their opinions about this situation.

"When I encounter problems, I sometimes tend to act with the feelings of mercy and affection instead of the professional solutions and take more responsibilities than I want or should take. Then a personal burden weighs on your shoulder rather than professional responsibilities." $(P-7)$

Low self-awareness: Being aware of strengths and weaknesses in terms of personal and professional competence is significant in order to act, improve and transform in the benefit of both themselves as school counselors and the target population. In time, psychological counselors gain awareness and improve themselves. However, they need to face with their qualities more which they need to improve as a psychological counselor in a professional sense. At the point of attempting to overcome this or thinking and acting, conflicts may emerge. Seven out of nine participants expressed their opinions about this situation.

\begin{abstract}
"Also, I see two profiles. One of them considers themselves as very well-equipped despite being insufficient, and acts with their own truths adding more to them. On the other hand, there is a crowd that considers themselves as very insufficient, yet they do not make an effort. There is another group that is very well aware of themselves and try to gain skills; however, they pile up in two edges." $(P-2)$
\end{abstract}

Lack of skill and specialization: School counselors experience the deficiency in the point of considering themselves as EPC, especially in skill and specialization. While some psychological counselors try to compensate this by getting therapy trainings or postgraduate educations, some psychological counselors assume that this insufficiency can be tolerated in the process with experiences and continue with the partial comfort of being alone. Five out of nine participants expressed their opinions about this situation.

"I have a good theoretical background because of good courses in university but in practice I feel weak. I mean in transferring what I learnt into practice. I feel I am at the beginning of my career path. I also don't have opportunity to develop myself." $(P-4)$

\title{
Discussion and Conclusion
}

Research findings suggest that EPCC such as self-awareness, good intentions, and flexibility, as well as therapy training received after graduation, were predictors of the 
empowerment needs of school counselors. In the qualitative part of the study, while the non-progressive to develop (inability to develop), differences in the job description and profession, negative personality traits and lack of knowledge and skills themes emerged for empowerment needs, the illusions in psychological counselor perception, nonprofessional good intentions, low self-awareness and lack of skills and specialization themes have emerged for EPCC.

When the psychological counselors start their work life with the acquisitions from their university education, their perception of a psychological counselor that they gain during their education conflicts with the definition of psychological counselors at schools (IIlhan et al., 2012). The main reason is guidance teachers and psychological counselors' working in the same counseling departments. This causes a conflict between the guidance teachers and the graduates of psychological counseling and guidance (Bonebreak and Borgers, 1984; Perusse et al., 2004). In order to speak of an appropriate profession related perception, roles and responsibilities of the profession as well as of the professional identity must be clarified (Sabancioğlu and Doğan, 2012). Under these circumstances, the majority of the energy of psychological counselors is spent on expressing themselves to school administration, teachers, parents and work partners that come from other academic fields and on trying to protect their rights instead of giving counseling services. Yet, instead of expecting psychological counselors to act in leadership roles or do tasks that are out of the school areas can provide them with the opportunity to search and evaluate programs, and to do verifiable jobs that are in benefit of the students (Whiston and Sexton, 1998). As emphasized in American School Counselor Association (ASCA), professionals of a job need an occupational frame or model that includes a consistent identity (ASCA, 2016).

The expectations and job perceptions of school administration, teachers and parents that are different and not appropriate to the definition of the profession (Aldemir and İlhan, 2018) sometimes lead psychological counselors to burn-out, decrease their energy or cause them to put negative personality traits forward to protect themselves. This can turn into laying the burden on other colleagues and avoiding doing their own duties by alleging various excuses and taking advantage of the situation in order to feel more competent and stronger in the profession and in order to be affected by the ambiguity of the process and problems less. Another problem that emerges here is that the effectiveness of the provided services' not being able to be measured. A psychological counselor is expected to be farsighted, willing and able to achieve desired aims in the context of effectiveness. Since there is an insufficient clarity and standard in the definitions of advisory teacher staff in the directives (Aldemir and İlhan, 2018), different styles emerge depending on the trainings, personality traits and perception of profession primarily in the teachers from different fields including psychological counselors. This situation leads psychological counselors working at schools to the different ways of perception in parallel to both psychological counselor characteristics and empowerment needs. This can be seen in illusions in psychological counseling sub-category of psychological counselor characteristics and differences in job description and perception sub-category of empowerment needs. Psychological counselors participating in the research classify different characteristics while defining a qualified psychological counselor, and they are aware of the differences among colleagues. This situation which stems from contradictions in terms causes differences in functioning at the institutions that the service 
is provided (Hatch, 2008).

The school counselors are ambidextrously (such as themselves, the institution, population and colleagues) in need of the elimination of the differences in the job description and perception in the context of empowerment needs. The existence of this difference also affects the quality of the provided service. The findings of the current study are compatible with the findings of the research of Aldemir and Illhan (2018). While they are expected to act in the basis of scientific knowledge and skills, it can be seen that the context of the education received and the service fields of the institution that they work do not exactly have the content to satisfy the need. Therefore, the service mentality that centers personal-cultural values move ahead of technical and scientific knowledge which is based on knowledge and skill. The participants reported that they feel the lack of skill and specialization while sharing their observations and experiences about themselves and their colleagues; therefore, they do not consider themselves qualified in this sense. This situation which becomes prominent as a subcategory in the satisfaction of empowerment needs is the lack of knowledge and skill. They protect the wellbeing of their clients in the services provided to their target population, whereas mercy, religious and moral values, cultural experiences become prominent in the support services. Although good intentions that belief and culture also prioritize are partly based on science and profession, they are reflected more around these values. Empirical and deeper data proving that personalcultural values are more functional or better than occupational knowledge and skills is needed (Brown and Trusty, 2005; Carey et al., 2008).

With the effect of the illusions in psychological counselor perception and the lack of skill and specialization, the support mechanism is effectively proceeded. This may lead the psychological counselor to take the responsibility of the client or co-workers and to produce solutions in their names. This process may cause the psychological counselor to feel functional and effective. Thus, these conditions may cause lesser amount of need to the intellectual efficiency and energy for the psychological counseling process. In this structure where standardization is not dominant, an occupational or personal routine which works within itself is dominant. Hall monitoring, being a substitute for the teachers in lessons, being involved in the curriculum plan (which includes annual exercises), conducting in-class activities in the context of determined activities, organizing parent seminars, interviewing with the teachers and parents of students who are contacted because of their problems (depending on the problem, this includes employing methods such as referring the student to a guidance research center or a psychiatrist, offering the students to change the class or school, or giving advice to the students) in this routine cause the supervision training that is received during bachelor's education to become unfunctional. In stages like high schools, parents do not lean towards counseling students to appear in lessons, and the interviews that are conducted during lunch breaks or after school are insufficient for hundreds of students; therefore, this causes not maintaining continuity in the interviews that are conducted. One of the researchers observed that the parents find interviewing students during lesson more favorable in primary school; however, the school counselors cannot provide a quality service since the trainings received during bachelor's degree do not support the skills related to the techniques about performing interviews with children. That the colleagues' working in the same field experiencing similar situations prevents a quality consultation as well. Some psychological counselors turn their steps towards paid therapy or skill/material use 
trainings (SFBT, EMDR, interview techniques with children and adolescents, play therapy, children-oriented test training) from the centers that provide therapy trainings depending on their institutions, populations or professional aims (such as specialization in a certain approach) when they encounter such limitations. Although the Ministry of National Education offers in-service trainings of a couple of days or hours towards the field of expertise, the practice and supervision parts of these training sessions are insufficient. This situation causes the school counselors to feel that therapy training is more efficient in satisfying the need instead of supervision training. Otherwise, conducting skills that are obtained with supervision training, which is generally theoretical and limited during the bachelor's degree education, without distinguishing population or institution brings about some risks. The flexibilities through which the subject content is transferred and integrated into the work life may lead the personal choices to become prominent instead of specialization and scientific values. This situation may cause even more practice variations in provided services. According to Stockton and Güneri (2011), the psychological counseling trainees in Turkey rarely have the opportunity to conduct counseling sessions in real-life situations. According to a study conducted by Özyürek (2009), it is revealed that the supervision training that psychological counseling students receive during their education is carried out with a great number of students and generally are given in an ineffective way by supervisors that do not possess sufficient efficiency that is required. According to Feldstein (2000), supervision training requires establishing a one-on-one relationship with supervisors and has to be intense and interpersonal-oriented. However, the practices in Turkey does not involve such situations.

The reason why supervision training received during bachelor's degree does not have any effect on empowerment which is also the obtained finding in the current study can be explained through the problems faced during the supervision process in Turkey. Although psychological counselors are aware of the insufficiencies brought by the experienced problems, they tend to prefer holding other colleagues and existing educational and occupational system responsible for the situation instead of turning to self-criticism. This situation prevents sharing knowledge and skill, which is the supportive part of sharing experiences with colleagues in practices as emphasized by Esen-Çoban (2005). It is thought that low levels of self-awareness and educational and systemic insufficiencies cause psychological counselors to become non-progressive for development by reducing the will and motivation of psychological counselors in terms of self-development and maturation. When the overall situation is evaluated within the context of empowerment dimensions, needs related to social activism and autonomy cannot be satisfied in the existing circumstances. Self-value in terms of occupation is far away from reality. It is thought that there is dissatisfaction and anger arising when they believe they control themselves in work life and that work life system causes them to feel weak. As obtained in the study, the received therapy training also reduces the empowerment needs of the psychological counselors. It is a hopeful result for psychological counseling field that primarily professional development is a life-long learning process (Orlinsky et al. 1999) and approximately half of the psychological counselors (46\%) improved themselves by receiving therapy training after they graduate.

In order to allow psychological counselors to perceive themselves as more qualified and to reduce their empowerment need by providing services, educational programs in Turkey 
should assure a standard. There indeed is a need for developing the competence of the supervision trainers as well as including supervision trainings that are related to the individuals from different developmental processes. The cost of therapy training prevents school counselors from preferring them. In order to reducing the cost and to allow school counselors to become more qualified, therapy trainings can be regulated as in-service trainings as much as possible since this can reach a wider group of counselors. The confusion and difference in the professional identity perception should be prevented. It is thought that providing supervision trainings with the support of universities in order to prevent the uncertainties, confusions and uneasiness especially in the first years of work can be effective in terms of the quality of service and work orientation. It is suggested to the psychological counseling trainers that not only skill acquisition but also subjects such as empowerment and social justice should be focused on during the psychological counseling trainings. The findings of survey research conducted by Kemer and Aladag (2013) in order to reveal the continuum of the supervision process in the context of psychological counseling practice which is included in Psychological Counseling and Guidance program revealed that less than half of the psychological counseling trainers who participated in the research based the supervision process on supervision model and that the model which is predominantly based on is developmental supervision models. It is suggested that the practices must be increased considering different supervision models (micro skill supervision model, developmental supervision model, and theoretical supervision model integrated supervision model and alike.). Furthermore, research concentrating on models unique to Turkey which display the professional development process of psychological counseling students in Turkey will be beneficial (Aladağ et al., 2014). In the literature, studies on the therapy training after graduation or the effectiveness of the therapy training cannot be found. Therefore, it is also suggested that future research should focus on the received trainings after graduation. According to Bernard and Goodyear (2004), it is suggested that more studies on the effectiveness of the provided supervision training to the school counselors should be conducted. In parallel with this suggestion, more studies should be conducted on the effectiveness of supervision training in Turkey. In order to prevent the lack of material and wrong expectations at the institutions where school counselors work and to provide solidarity between psychological counselors, profession associations can be established. Finally, it is thought that the studies need to be extended even more in order to restructure the programs that educate psychological counselors or to accredit them (Doğan, 2000). One of the limitations of this research is that qualitative findings are limited to the analysis of the researchers. It would have been helpful to include the support of an outside expert in the process. What is encountered in professional life and competence areas may differ related to geographical regions. In this sense, in order to ensure representation, it might be suggested to include psychological counselors who work in different regions of Turkey for next set of studies. It is thought that in so doing will enrich/diversify the findings especially in the qualitative part. It is thought that research needs to be structured by taking all these needs into consideration.

\section{Acknowledgements}

We would like to thank heartfully to the school counselors who agreed to participate in our research and opened up themselves during in-depth interviews. 


\section{Note}

This research was presented on 20. International Psychological Counseling and Guidance Congress on 25.10.2018, Samsun, Turkey.

\section{References}

Akkoyun. F. (1995). Degree and problems of program in psychological counseling and guidance program: A review and recommendations. Turkish Psychological Counseling and Guidance Journal, 2(6), 1-21.

Aladağ, M., \& Bektaş, D. Y. (2009). Examining individual-counseling practicum in a Turkish undergraduate counseling program. Eurasian Journal of Educational Research, 37, 53-70.

Aldemir, A., \& İlhan, T. (2018). A study on the professional perceptions of school counselors. Turkish Psychological Counseling and Guidance Journal, 8(51), 5380.

Andrews, D., Nonnecke, B.\& Preece, J. (2003) Electronic survey methodology: A case study in reaching hard to involve Internet Users. International Journal of HumanComputer Interaction. 16(2), 185-210.

Anjel, M. ve Özkan, R. (2009). Türkiye'de PDR alanında gözetim: Bir durum saptaması [An analysis of Counseling in Turkey]. Reached at 11.09.2020 on http://www.yoret.org.tr/Bilgi.asp

ASCA, (2016). ASCA ethical standards for school counselors. https://www.schoolcounselor.org/asca/media/asca/Ethics/EthicalStandards2016. pdf

Bernard. J. M. \& Goodyear. R. K. (2004). Fundamentals of clinical supervision (3rd ed.). Boston: Allyn \& Bacon

Borders, L. D. \& Brown, L. L. (2006). The new handbook of counseling supervision. CRC Press.

Brown, D., \& Trusty, J. (2005). School counselors, comprehensive school counseling programs, and academic achievement: Are school counselors promising more than they can deliver?, Professional School Counseling, 9(1), 1-8.

Carey, J. C., Dimmit, C., Hatch, T., Lapan, R. T., \& Whiston, S. C. (2008). Report of the national panel for evidenced-based school counseling: Outcome research coding protocol and evaluation of student success skills and second step. Professional School Counseling, 11(3), 197-206.

Carr, E. S. (2003). Rethinking empowerment theory using a feminist lens: The importance of process. Affilia, 18(1), 8-20.

Carkhuff, R. (2011). The art of helping, (9th Edition). HPD Press.

Cormier, W. H. \& Cormier, L. S. (1991). Interviewing strategies for helpers (3. Ed.). Pacific Grove, California: Brooks/Cole Publishing Company.

Cormier, S., Nurius, P. S. \& Osborn, C. J. (2009). Interviewing and change strategies for helpers. (6. Ed.). USA: Brooks/Cole, Cengage Learning.

Creswell, J. W., \& Plano Clark, V. L. (2011). Mixed methods research: Designing and conducting. Los Angeles: SAGE.

Çakır, S. G., \& Bugay Sökmez, A. (2017). Pychometric properties of empowerment scale. The Journal of Academic Social Sciences, 5(57), 40-53.

Doğan, S. (2000). The need for accreditation in counselor education: A recommended model. Turkish Psychological Counseling and Guidance Journal, 2(14), 31-38. 
Erkan-Atik, Z., Arıcı, F., \& Ergene, T. (2014). Supervision models and assessments of the models. Turkish Psychological Counseling and Guidance Journal, 5(42), 305317.

Eryılmaz, A., \& Mutlu, T. (2018). Counselor trainees' opinions related to the developmental comprehensive supervision model. Electronic Journal of Social Sciences, 17(65), 123-141.

Esen-Çoban, A. (2005). Psikolojik danışmanlar için meslektaş dayanışması [Colleague collaboration for psychological counselors]. Mersin University Journal of the Faculty of Education, 1(1), 167-174.

Field, A. (2009). Discovering statistics using SPSS (3 rd ed.). Los Angeles: SAGE Publications.

Feldstein, S. B. (2000). The relationship between supervision and burnout in school counselors (Unpublished doctoral dissertation). Duquesne University, Pittsburg, PA.

Field, A. (2005). Discovering statistics using SPSS (2nd ed.). Los Angeles: Sage Publications, Inc.

Hatch, T. A. (2008). Professional challenges in school counseling: Organizational, institutional and political. Journal of School Counseling, 6(22), 1-31.

Hill, C. E., Stahl, J. \& Roffman, M. (2007). Training novice psychotherapists: Helping skills and beyond. Psychotherapy: Theory, Research, Practice, Training, 44(4), 364.

Hipolito-Delgado, C. P., \& Lee, C. C. (2007). Empowerment theory for the professional school counselor: A manifesto for what really matters. Professional School Counseling, 10(4), 327-332.

Hsieh, H. F.\& Shannon, S. E. (2005). Three approaches to qualitative content analysis. Qualitative Health Research, 15(9), 1277-1288.

Ivey, A. E. \& Ivey, M. B. (2003). Intentional interviewing and counseling: Facilitating client development in a multicultural society. Pacific Grove, CA: Brooks/ ColeThomson Learning.

İkiz, F. E., \& Totan, T. (2014). A scale developing to assess effective counselor characteristics. Turkish Psychological Counseling and Guidance Journal, 5(42), 269-279.

İlhan, T., Korkut-Owen, F., Furr, S. ve Parikh, S. (2012). International counseling students in Turkey and their training experiences. International Journal for the Advancement of Counselling, 34(1), 55-71.

Kemer, G. \& Aladağ, M. (2013). Counseling practicum and supervision in counselor education: A national survey. In World Congress of Psychological Counseling and Guidance, Istanbul, Turkey.

Özyiğit, M. K., \& İşleyen, F. (2016). Supervision training in counseling. Abant Izzet Baysal University Journal of Faculty of Education, 16(4).

Lee, C. C. (1991). Empowering young black males. https://files.eric.ed.gov/fulltext/ED341887.pdf

Lyddon Jr, W. J. (1995). Cognitive therapy and theories of knowing: A social constructionist view. Journal of Counseling \& Development, 73(6), 579-585.

McWhirter, E. H., (1991), Empowerment in counseling. Journal of Counseling \& Development, 69, 222-227. 
McWhirter, E. H. (1994). Counseling for empowerment. American Counseling Association.

McWhirter, E. H. (1998). An empowerment model of counsellor education. Canadian Journal of Counselling, 32(1), 12-26.

Menard, S. (2002). Applied logistic regression analysis. Thousand Oaks: Sage Publications

Meydan, B. (2015). Examining the effectiveness of microcounseling supervision model in individual counseling practice. Turkish Psychological Counseling and Guidance Journal, 5(43), 55-68.

Miles, M. B. \& Huberman, M. (1994). Qualitative data analysis: An expanded sourcebook. (2nd ed.). Thousand Oaks, CA: Sage.

Orlinsky, D., Rønnestad, M. H., Ambühl, H., Willutzki, U., Botersman, J. F., Cierpka, M., ... \& Davis, M. (1999). Psychotherapists' assessments of their development at different career levels. Psychotherapy: Theory, Research, Practice, Training, $36(3), 203$.

Özyürek, R. (2009). The supervision opportunities for practicum students of school counseling provided to trainees in Turkish universities: A national surve. Turkish Psychological Counseling and Guidance Journal, 4(32), 54-63.

Palinkas, L. A., Horwitz, S. M., Green, C. A., Wisdom, J. P., Duan, N., \& Hoagwood, K. (2015). Purposeful sampling for qualitative data collection and analysis in mixed method implementation research. Administration and Policy in Mental Health and Mental Health Services Research. 42(5), 533-544.

Perkins, D. D. \& Zimmerman, M. A. (1995). Empowerment theory, research, and application. American Journal of Community Psychology, 23(5), 569-579.

Perusse, R., Goodnough, G. E., Donegan, J. \& Jones, C. (2004). Perceptions of school counselors and school principals about the national standards for school counseling programs and the transforming school counseling initiative. Professional School Counseling, 7(3), 152-161.

Poyrazlı, Ş., Doğan, S., \& Eskin, M. (2013). Counseling and psychotherapy in Turkey: Western theories and culturally inclusive methods. R. Moodly, U. P. Gielen, \& R. $\mathrm{Wu}$ (Eds.), In handbook of counseling and psychotherapy in an international context (pp. 404-414). New York, NY: Routledge.

Rogers, E. S., Ralph, R. O. \& Salzer, M. (2010). Validating the empowerment scale with a multisite sample of consumers of mental health services. Psychiatric Services, 61, 933-936.

Siviş-Çetinkaya, R. \& Karairmak, Ö. (2012). Supervision in counselor education. Psychological Counseling and Guidance Journal, 4(37), 107-121.

Stockton, R., \& Güneri, O. Y. (2011). Counseling in Turkey: An evolving field. Journal of Counseling \& Development, 89(1), 98-104.

Tabachnick, B. G., \& Fidell, L. S. (2013). Using multivariate statistics. Allyn \& Bacon/Pearson Education

Taherdoost, H. (2016). Sampling methods in research methodology; How to choose a sampling technique for research. International Journal of Academic Research in Management, 5(2), 18-27.

Yeşilyaprak, B. (2009). The development of the field of psychological counseling and guidance in Turkey: Recent advances and future prospects. Ankara University Journal of Faculty of Educational Sciences, 42(1), 193-213. 
Y1lmaz, O., \& Acar, N. V. (2015). The importance of supervision in psychological counselor training and its role in group counseling. Bolu Abant İzzet Baysal University Journal of Faculty of Education, 15(1), 342-356.

YÖK, (2007). Öğretmen yetiştirme ve eğitim fakülteleri [Teacher education and education faculties]. https://www.yok.gov.tr/Documents/Yayinlar/Yayinlarimiz/ogretmen-yetistirmeve-egitim-fakulteleri.pdf

Whiston, S. C., \& Sexton, T. L. (1998). A review of school counseling outcome research: Implications for practice. Journal of Counseling \& Development, 76(4), 412-426.

Worthington Jr, E. L. (2006). Changes in supervision as counselors and supervisors gain experience: A review. Training and Education in Professional Psychology, 2, 133-160. 